\title{
USE OF AN INDIGENOUS LEARNING BUNDLE IN AN ENGINEERING Project Course
}

\author{
Alan L Steele ${ }^{1}$, Cheryl Schramm ${ }^{2}$, Kahente Horn-Miller ${ }^{3}$ \\ ${ }^{1}$ Department of Electronics, ${ }^{2}$ Department of Systems and Computer Engineering, \\ ${ }^{3}$ School of Indigenous and Canadian Studies, Carleton University \\ alan.steele@carleton.ca, cheryl.schramm@carleton.ca, kahente.hornmiller@carleton.ca
}

\begin{abstract}
In response to the Calls to Action of the Truth and Reconciliation Commission of Canada a range of Collaborative Indigenous Learning Bundles have been introduced at a Canadian university to provide ways for Indigenous knowledge to be incorporated into courses across the university. One of the first courses in the engineering faculty to use the Indigenous Environment Relations Bundle was a third year project course for the BEng Electrical Engineering program. The use of the bundle, through the learning management system, was part of the lecture series and was used in a class discussion with an optional reflection. The objective was to provide complementary Indigenous knowledge to the discussion of the environmental impact of engineering. A first year introductory engineering course used the First Peoples: A Brief Overview. The response of the students in both courses was respectful and produced thoughtful discussions. Those that undertook the optional reflection produced insightful and often personal thoughts on a particular place. The use of the bundles shows that Indigenous matters and information from knowledge keepers can be integrated into engineering courses.
\end{abstract}

Keywords: Engineering Education, Engineering Project, Indigenous Learning, Environmental Relations, Truth and Reconciliation Commission of Canada.

\section{INTRODUCTION}

In the introduction to the 2015 summary report of the Truth and Reconciliation Commission (TRC) of Canada there is the statement, "Canadians have much to benefit from listening to the voices, experiences, and wisdom of Survivors, Elders, and Traditional Knowledge Keepersand much more to learn about reconciliation." [1]. The Calls to Action [2] that resulted from the report made 94 specific calls to groups and individuals to help support and facilitate reconciliation, including (but not limited to), governments, media, business, newcomers to Canada and education. In the education section there are specific calls for support including in Call 62 ii [2],
"Provide the necessary funding to post-secondary institutions to educate teachers on how to integrate Indigenous knowledge and teaching methods into classrooms."

As well as Call 63 iii [2],

"Building student capacity for intercultural understanding, empathy, and mutual respect."

In response to these Calls to Action post-secondary institutions have been working towards developing ways to support the calls [3], including creating courses, resources, committees, faculty and support positions. Members of professions and disciplines have been looking at how their courses in post-secondary institutions can rise to the challenge of the Calls to Action; for example in early childhood education [4], nursing [5], history [6] and geography [7].

At Carleton University the approach to help students and their faculty has been the introduction of Collaborative Indigenous Learning Bundles [8] that can be incorporated into any course. These bundles cover specific topics and include a forty minute lecture, an interview with an Indigenous Knowledge Keeper who engages with the lecture content, passing on lived experiences and information on the topic. Additional resources like readings and videos help the instructor to bridge the content of their course and the Indigenous knowledge in the Bundle. A faculty member incorporates the bundle into their course through the learning management system and shares it with their students. There is enough content in a Bundle for one class.

Engineers, like all professions, in Canada need to be aware of the Truth and Reconciliation Calls to Action [2] and so including the bundles in an engineering program is important at both an educational level for individuals, but also at a professional level. Incorporating the collaborative Indigenous learning bundles into engineering courses at first glance may be a challenge, due to the perceived relevance. However, because of the modular nature of the bundle and the range of topics, there can be opportunities for the bundles to complement existing course material with Indigenous knowledge and respond to the call for action. In this paper we describe the inclusion of the 
Indigenous Environmental Relations bundle [9] into a project course in the Electrical Engineering program. This course already had a lecture component on environmental issues and so the inclusion of bundle could be accommodated.

As a way of showing the modularity of the bundles we will also show the inclusion of a different bundle, First Peoples: A Brief Overview, [10] into an introduction to engineering course for first year students. Both of these courses are the initial attempts to include bundles into engineering courses. We describe and discuss the use of the bundle in the two courses but will focus mainly on the project course. There will be details of the inclusion of the collaborative learning bundle. The observed student responses to discussions about the bundles' content will be detailed, and for the project course an overview will be given of the responses to a reflection based on a resource included in the bundle.

\section{THE CARLETON INDIGENOUS LEARNING BUNDLES}

\subsection{Origin of the Bundles}

The proposal for the Collaborative Indigenous Learning Bundles (CILB) at Carleton was by Dr Kahente HornMiller, one of the authors of this paper. The idea was for a more collaborative and integrated approach to adding Indigenous knowledge into the curriculum of programs across Carleton. This was based upon knowledge sharing and uses the idea of the Dish with One Spoon Wampum Belt [11] to represent the sharing of knowledge from the common pot. In the Spring of 2018 support for the CILB initiative was given by the then Interim Provost. The first bundles were available for use in the 2019-2020 academic year. For a spoken explanation on the creation of these Bundles there is a video recording of the CILB originator at the website [8].

The idea of the CILB was to provide expert knowledge from Indigenous faculty as well as Indigenous Knowledge Keepers, that could be used in existing courses. The information in the bundles could then be used to in the courses in a way that brings in authoritative Indigenous knowledge on a subject matter that can complement the course. Interested course instructors gain access to and instruction on use of the bundles through the Education Development Centre (part of Teaching and Learning Services) at Carleton. They are guided in bridging the content of their courses and the bundle content. The bundles are available through the learning management system and so can be made easily available to the instructor for use with students. Each bundle comprises of about 40 minutes of instruction from the specific bundle's creator, including questions. There is then further information from an Indigenous Knowledge Keeper, either through audio or video recording and finally suggested activities for the instructor to use with students. No more than two bundles can be used in any course.

The number of bundles have been increasing and the list of bundles at the time of the writing of this paper was [8]:

- The First Peoples: A Brief Overview

- Decolonization is for Everyone: Identity Formation in the Canadian Context

- Engaging with Indigenous Communities

- Indigenous Environmental Relations

- Indigenous-Canada Relations

- Introduction to the Metis People and the Metis Nation

- Cultural Conceptions of the Life Cycle

- The Inuit Story

- Maternal and Child Health

- Determinants of Health

- Indigenous Law and Conceptions of Human Rights

\section{APPROACH TO USING THE INDIGENOUS LEARNING BUNDLE}

\subsection{Introduction to the Project Course}

The engineering course into which the learning bundle was included was a mandatory third year course for the BEng Electrical Engineering program at Carleton called Engineering Project with the code ELEC3907. This single term course was established in 2013 and was created to be a group project involving design. The course requires a group of five to seven students to select, design, build and test an electronic project. Sample past projects include; a robot to map the perimeter of a room, a driveway salting robot, child memory game, a Braille printer, an automatic guitar tuner and a controlled hydroponic plant growing system. The choice and scope of the project is up to the students. This requires the students to consider their knowledge and ability. Besides the student selected projects there has been an attempt to collect client based projects, so this has included project ideas that have come from for example: biologists - a insect habitat control and monitoring system; artists - an audio playback system that would play recordings to headphones when a person viewed a photograph at different positions relative to the photograph; an office building management company - a project to incentivize cycling to and from the office.

Students in the course had six hours scheduled ( $2 x$ three hours) in the lab rooms to work on the projects and $2 \mathrm{x}$ one hour lectures in a class room. The lectures covered various aspects relating to the project including working in groups, programming of micro-controllers, aspects on design, ethics and environmental aspects and sustainability. There have also been guest lectures including from an RF circuit designer and an industrial designer. In the lecture periods 
there were also presentations from the students at various stages that covered the proposed project, design details, one thing the group had learned and a final presentation to show what had been achieved.

\subsection{Including the Bundle into the Project Course}

With the release of the Carleton Indigenous Learning Bundles in 2018 there was an opportunity to introduce one of these bundles to the Electrical Engineering program through the course. The bundle that fitted well into this course was the Indigenous Environmental Relations. The modular design of the bundle allowed the instructor, after working with the support staff to engage with the content and find links to their course content, to easily include it to complement the information on the environmental aspects already in the course.

The bundle [9] was introduced through the learning management system and students were asked to complete the bundle before a schedule lecture. It should be stressed that the course was a project course and not focused solely on environmental aspects. However, as part of a series of lectures on different aspects relating to project work and design, this bundle fitted into the final lecture on environmental impact. The bundle provides an Indigenous perspective on the relationship that living beings, including man, have with the environment. As well there is a context that includes more theoretical perspectives that can help with positioning the Indigenous content and aligning it with what is taught in the course. The first part of the bundle is delivered by an Indigenous professor, providing the academic context and later there is an audio interview with an Indigenous Knowledge Keeper. The knowledge keeper's perspective provides a first person's account of a relationship with not only the environment but also society, providing a depth and breadth to the discussed concepts.

After students had been requested to work through the bundle there was a discussion in one of the hour classes guided by the instructor. At the start of the class session a short video was shown of an interview of the makers of the film Anthropocene by the then Canadian Minister of Environment and Climate Change (at the time of recording) [12]. Along with the interview the video showed excerpts of the movie that indicates the impact man has on the environment. It also discussed the approaches the film makers took to make the material accessible, including the use of virtual reality.

Following the video and directly before the discussion, the instructor provided a model of how an individual's perspective and opinion could be formed, Fig. 1. The intention of including it was to show how individuals had a perspective formed from various elements of their lives, and to create a respectful environment open to the opinions of all. Being a class of engineering students the common factor of an engineering perspective was central to the framework in Fig. 1, but 'engineering' could have been made more general by being replaced with 'career'. The model then shows that an individual's past, culture and future hopes and goals can help shape their perspective, rounded out by the individual's personal philosophy, (which could include politics) along with spirituality (which could include religion). Being a simple framework as to what shapes our opinion and views this was an attempt to remind all in the room that individuals had differences and the hope was that each view and individual should be respected.

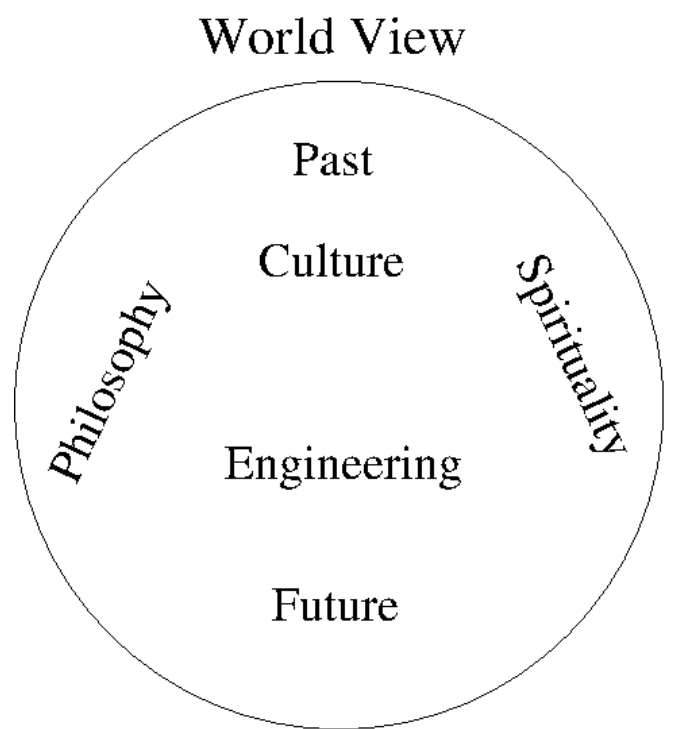

Fig. 1. A simple framework used to show the influencing elements as to how the world perspective of an individual (and student of engineering) can be shaped.

Following the class session a reflection was offered, through the learning management system, which was taken from a set of instructor resources that were included in the bundle. Throughout the project course a series of reflections were required, with a total of five reflections being done across the term. This reflection from the bundle was included in the fourth reflection which became a choice of one of two questions for reflection. One option was a reflection on how the student would maintain the upkeep of their knowledge over their working career. Alternatively, the Collaborative Indigenous Learning Bundle reflection question was:

"Pick a landscape or a place that is
meaningful to you. Describe it (you
could include a photograph),
describe how it makes you feel and
how you came to know this place-
i.e.: Is it a place your family visits? Is
it a vacation spot? A favorite park?
A picnic spot? Explain why this place
is meaningful to you and what human
and non-human relations are shaped
by this place/landscape. You may


want to consider and comment how human design has affected this place. ”[9]

\subsection{Including a Bundle in a New Introductory Engineering Course}

A new curriculum for all first-year engineering students in the fall of 2019 provided an opportunity for introducing Indigenous perspectives at the onset of their engineering career for all engineering students. The course Introduction to Engineering Disciplines, ECOR1055, is an overview course - without the typical professor-in-charge, instead consisting of separate lessons from both individual faculty members and visitors- on the nature of professional activities encountered by practicing engineers in Canada. One of the authors (CS) volunteered to lead a lecture on Indigenous Peoples of Canada.

The learning objectives for this single lecture were: To establish vocabulary definitions concerning Indigenous peoples; to compare an Indigenous world view with other world views; and, to demonstrate the relevance and importance of Indigenous peoples to engineering in Canada. The bundle chosen for use in this course was First Peoples: A Brief Overview [10]. The bundle is intrinsically an introduction and its contents were perfectly suited to the learning objectives of the lecture: Important terms; What is Colonization? Major issues (Reserves, Residential Schools, Missing and Murdered Indigenous Women (MMIW), Systemic Racism).

Because each lecture is a separate delivery in ECOR1055, all activity was done during the 1.5 hour lecture (No preparation or homework was given). The lecture used the image of a circle as its connective tissue. The lecture was deliberately held in a different location, in the Discovery Centre [13], a unique learning space at the university equipped with moveable furniture and collaborative technology. As students congregated, they were invited to draw up a chair or a sofa into a circle, one from which two large screens were visible.

The purpose of first activity in the lecture was to learn vocabulary. With an international population in engineering of $19.3 \%$ [14] it cannot be assumed that these students know that the use of word Indian is problematic, that our Indigenous peoples are made up of many First Nations, not a monolithic unit, let alone understand the history behind the Calls to Action from the Truth and Reconciliation Commission (TRC). A PowerPoint lecture from the bundle on important terms - presented in a recorded video by the third author (KHM) - was viewed. It was important that this initial presentation was given in the voice of an Indigenous person, rather than on behalf of. A portion of the Knowledge Keeper's interview was also viewed: Mi'kmaq Elder, Stephen Augustine introduced himself (in the traditional way, by talking about place and relations) and talked about the common myths. With guidance, students were exposed to the mix of terms used by Stephen Augustine in talking about myths while seeing the humour and resilience of this elder. An excerpt of one portion discussed is: (bold added to show the vocabulary)

"Common myths, I mean, some
people think we're still living in tee-
pees and riding horses. I mean, it's a
common pan-Indianism kind of
concept, that was kind of encouraged
and developed by this guy named
Karl May ...He made movies, and
they depicted Indians riding horses,
yelling and screaming, and
whooping, riding over the hill. And I
think that's a big misconception
about Indigenous people in North
America.
And others are more related to we
don't pay taxes, and we're savages.
[Laughs] There's a misconception
thatwe're not educated, andwe don't
know anything much about
mainstream society. We're not equal
to mainstream non-Indigenous
people." Stephen Augustine, [10]

The activity ended with a light quiz from the bundle, done as a large group, to check their knowledge.

The term "Indian" is the current
legal definition regarding many
Indigenous people in Canada today,
despite it being considered offensive
by most Indigenous individuals. True
or False.[10]

The second activity was intended to introduce the notion of a world view. Discussion now shifted to the word "contract". After eliciting students' definitions and establishing that we generally shared the notion of a contract as being a written document, the Two Row Wampum Belt [15] was introduced. A wampum belt is ostensibly a flat drawing using simple geometric designs made up of woven beads, but is in fact a mnemonic device used to document a relationship between two peoples. The Two Row Wampum treaty is an agreement between the Haudenosaunee and the Dutch in 1613. With this example, the students were exposed to an Indigenous world view in which ceremonies, symbols and oral history form treaties of as much validity and longevity as our modern written contracts. 
The shift in discussion from written to images - where a contract can be oral and symbolized, not written - segued to the final activity. Students were polled on their familiarity with the Iron Ring, on the story, on its symbolism of professionalism, and on its imagery of a young person being rough on the edges and being worn smooth by time, experience and wisdom. By connecting the symbolism of the Iron Ring to the symbolism of the Two Row Wampum belt, it was intended to reinforce a respect for the treaty contract, and our duty as engineers to upload those treaties in our professional life.

The lecture was concluded with the reading of Carleton University's Territorial Acknowledgement [16], traditionally read at the start of an event. Instead, ending the lecture with the reading was meant to connect the circle, with the students now empowered with more knowledge, so that they could actually join in with the acknowledgement.

\section{OBSERVATIONS AND DISCUSSION}

\subsection{Observations from the Project Course}

In 2020 the bundle was used in the course for the second time. There were 112 student in the course that year and from the information in the learning management system it was seen that 80 students (71\%) viewed the bundle, 29 (26\%) viewed completed all of the bundle and $45(40 \%)$ had multiple visits. The average time with the bundle was 1 hour 6 minutes, the longest time was 4 hours 34 minutes and the shortest was 24 seconds. This indicates a majority of students not only visited the site but worked through the bundle.

The discussion session was delivered by one of the authors (ALS) who is non-Indigenous and was born in Europe (this ethnicity was stated to the students at the start of the discussion), and observed by another of the authors (CS). In both years of including the bundle in the course the number of students admitting to having worked through the bundle at the start of the discussion was low. In the second year of offering there were approximately 10 to 15 students who indicated they had worked through the bundle for the class session. Attendance to the lecture class sessions was about 35 students, which was not uncommon for the latter half of the course, as this project course was mostly laboratory based. The reduction of attendance to the classroom sessions has been noticeably lower in the last half of the term. When students are asked why the lower attendance, the response (from those attending) was that the lack of an exam in the assessment could be the reason. In the second year of using the bundle the number of students indicating they had viewed it was higher than the previous year and this may be linked to more emphasis being given that this would be discussed and that it would feature in the next of a series of reflections the students have to take.
The discussion ideally would have been done in a circle format so it was easier for all to see each other face to face, but the classroom was a traditional lecture layout. To reduce the risk of a perceived lecture style format the instructor sat on a chair at the front of the lecture room and encouraged all to contribute to the discussion.

The discussion commenced without difficulty and there was a range of voices heard. A few individuals did the majority of the talking, but one surprise to the instructor was the contribution from some students who did not usually, or had never contributed. Some themes of points raised were.

- The Indigenous perspective on the environment was different to their perspective and it was "grounding" and "a fresh perspective"

- The damage mankind has had on the environment was acknowledged, but as students they felt powerless to change this, beyond contributions like recycling. Though they thought they could make change once working.

- With regards to the environment and Indigenous relations there was a feeling amongst some students they had blame pointed at them, and raised that this was a fault by past generations. They felt there was only so much change they could do.

- When the issue of unceded land was raised (after checking the word 'unceded' was understood) there was again a sense of helplessness about what could be done to change this. Again, there was a feeling of blame for past decisions.

- When asked if Canada was still a EuroWestern society there was expressed pride in Canada being a multicultural society and they favoured the diversity of ethnicity.

When the session was coming to a close the emphasis of the challenge of changing things being either impossible or severely challenging was noted by the guiding instructor. Not wanting to leave a sense of hopelessness the instructor gave his thoughts on the changes seen in his lifetime with major issues which had seemed irreconcilable at times.

Subsequent to the discussion the next scheduled reflection was given. As mentioned, this was a choice of reflecting on either life-long learning or the reflection question that had been provided with the bundle, as detailed in section 3.2. Of the 112 students 45 (40\%) chose to reflect on the question provided with the Indigenous learning bundle. Since the reflections usually focused on the project work these 45 reflections were different, but 
insightful for the reader. The places of significance were from all around the world and from cities to buildings, trails and paths, places visited, or places considered home. Usually a photograph was included and most of the places had stories relating to the student's lives and family. Most reflections included personal details and the instructor reading them got more of a personal history and insight about the student than usual. The student's work showed the reflection on the significance of a place and its environment to themselves. Some reflections showed how the ideas in the bundle had resonated with the writer, further showing they had studied and considered the ideas within it, including the knowledge keeper's wisdom. Although not seemingly directly related to the usual project work and engineering design, the exercise did relate the importance of the environment and so created a way to refocus the importance of the environment with their engineering work.

\subsection{Observations from the introductory engineering course}

Due to the nature of ECOR1055 Introduction to Engineering Disciplines - with a one-time lecture, with no preparation or homework - there is limited impact data collected. The class itself was attended by more than 100 students. The act of sitting in a circle in moving chairs and couches demanded more attention, with more eye contact and less phone distractions and no laptops in use. The first activity was listened to with the usual quiet politeness of students, but the discussion become more personal and reflective when asked to relate it to their own personal backgrounds. Contributions include small background stories about Indigenous peoples in South America and Australia, as well as black peoples in African countries. At the time, the Hong Kong student protests [17] were ongoing, and a brief discussion about the importance of protest, resistance and change was held.

The discussion in the final activity covered three main points. Firstly, engineering is more than technology, that engineering happens within a context, and that context especially here in Canada - includes Indigenous peoples. Secondly, learning about the Indigenous world view can open one's mind to alternative design solutions, an important stage in the engineering design process. Finally, we as engineers have a responsibility to consult with Indigenous peoples in engineering projects, when appropriate. While the discussion seemed well received, the impact has not yet been measured, and perhaps can only be measured in our subsequent efforts, such as the third year design course, described earlier.

\section{CONCLUSIONS}

We have detailed how a Collaborative Indigenous Learning Bundle was developed for use in courses across a university and how they can be incorporated into engineering courses. These bundles were created by specialists and Indigenous faculty and included recordings of Indigenous Knowledge Keepers. The details given here of the two courses are the first implementations in undergraduate engineering programs at Carleton, and among the first group of courses to use them in the university.

Although it may be considered a challenge to fit Indigenous learning into engineering courses the examples here show it is possible and can work well. In the first reported case here we implemented the Indigenous Environmental Relations Bundle [9] into a third year noncapstone project course. The course has elements of design through to environmental issues with electronic devices. The bundle fitted well within this course section and provided a way to learn Indigenous knowledge, from an Indigenous Knowledge Keeper, as well as consideration of environmental issues and engineering. The bundles were made available through the university's learning management system. Data shows that for the project course $71 \%$ accessed the information on the Indigenous Environmental Relations bundle and on average spent about an hour working through the material. Further consolidation of the information was done through a discussion. Although there was about a third of the students involved there was good engagement in the discussion. The overall response showed students considered the information carefully and seriously including an acknowledgment that the current issues relating to the environment and Indigenous relations are being inherited the solutions will be challenging.

Using the resources with the Indigenous Environmental Relations bundle the instructor provided an option to reflect on a place of significance to the students. $41 \%$ of the students reflected on this and provided a rich collection of places around the world including reasons why the places were significant. Some of these reflections showed the learning bundle had been studied and students had, to varying degrees, related their experiences to the Indigenous ideas in the bundle.

We have also reported on the use of another bundle, on The First Peoples: A brief overview [10] which was presented and discussed by first year engineering students in an introductory engineering course. Including a bundle in this foundational course can provide fundamental information on Indigenous information, of which many students many not be fully aware. Including such a bundle at an introductory stage allows the easier implementation of other bundles into later courses in the program, such as the project course also described here. It also shows the potential of scaffolding Indigenous knowledge through a degree program, so increasing engineering students to Indigenous knowledge as well as potentially broadening their world view and perspectives of others. 
As institutions look at how to answer the Calls to Action from the TRC report, this work shows that there is a possible approach for including Indigenous learning into existing courses, offering an alternative to a specific course on Indigenous matters. Using such a model it is possible that a student may take a number of courses that use the different bundles and so are exposed to different Indigenous ideas within the context of the subject of the course. A question could be raised 'what if the same bundle is encountered twice?' Currently, the Indigenous learning bundles are new at Carleton and so repeated encounters with a particular bundle is unlikely at the moment. (Note there is a community of practice emerging at Carleton as faculty from across the university start using the bundles). If there was to be a duplication, because another course may have a different context for introducing the bundle there may be a different perspective leading into the bundle, which will probably cause the student to consider the material from that other disciplinary perspective. Possible other courses that could use similar bundles could be courses covering professional practice, engineering economics, communications, technology and society or other technical courses that could use examples or casestudies relating to Indigenous aspects covered by the bundles.

In both courses described, the inclusion of the bundle took some study time of the student and a single scheduled class time for the discussion. The project course included one reflection exercise related to the bundle in a series of five. This was a relatively small part of the whole of each of the courses, but considered by the instructors of each to be a valuable investment of time. By including the Collaborative Indigenous Learning Bundle into the courses it created awareness of the TRC work and the resulting calls to action, whilst stressing the importance of it to the students' education and to engineering.

\section{Acknowledgements}

The authors acknowledge the support of the Collaborative Indigenous Learning Bundles team in the Education Development Centre at Carleton University.

\section{References}

[1] Truth and Reconcilliation Commission of Canada, Honouring the truth, reconciling for the future: summary of the final report of the Truth and Reconcilliation Commission of Canada. 2015.

[2] Truth and Reconcilliation Commission of Canada, "Truth and Reconciliation Commission of Canada: Calls to Action," Truth and Reconciliation Commission of Canada,
2015. Accessed: Apr. 23, 2020. [Online]. Available: http://nctr.ca/assets/reports/Calls_to_Action_English2.pdf.

[3] S. Treleaven, "How Canadian universities are responding to the TRC's Calls to Action," Maclean's, Dec. 07, 2018.

[4] B. Taylor, "Toward Reconciliation: What do the Calls to Action Mean for Early Childhood Education?," J. Child. Stud., vol. 42, no. 1, p. 48, May 2017, doi: 10.18357/jcs.v42i1.16887.

[5] S. Y. Blackstock, "Shifting the academic lens: Development of an interdisciplinary Indigenous health nursing course," $J$. Nurs. Educ. Pract., vol. 7, no. 1, Aug. 2016, doi: 10.5430/jnep.v7n1p11.

[6] L. Gibson and R. Case, "Reshaping Canadian History Education to Support Reconciliation," Can. J. Educ. Can. L'éducation, vol. 42, no. 1, pp. 251-284, Mar. 2019.

[7] S. de Leeuw, "Writing as righting: Truth and reconciliation, poetics, and new geo-graphing in colonial Canada: Writing as righting," Can. Geogr. Géographe Can., vol. 61, no. 3, pp. 306-318, Sep. 2017, doi: 10.1111/cag.12395.

[8] Education Development Centre, "Carleton University Collaborative Indigenous Learning Bundles (CILB)." https://carleton.ca/edc/carleton-university-collaborativeindigenous-learning-bundles-cucilb/ (accessed Apr. 23, 2020).

[9] Z. Todd and A. Dumont, Indigenous Environmental Relations: Carleton University Collaborative Indigenous Learning Bundles. Carleton University's Media Production Centre, 2018.

[10] K. Horn-Miller and S. Augustine, The First Peoples: A Brief Overview. Carleton University Collaborative Indigenous Learning Bundles. Carleton University's Media Production Centre, 2018.

[11] "Wampum belt," Museum of Ontario Archaeology, Jan. 23, 2015. http://archaeologymuseum.ca/wampum/ (accessed May 18, 2020).

[12] M. Millen, Edward Burtynsky, Jennifer Baichwal and Nicholas de Pencier on The Anthropocene Project. Canadian Geographic.

[13] Office of the Assoc. Vice-President Teaching and Learning, Carleton University, "The Discovery Centre." https:/carleton.ca/discoverycentre/ (accessed Apr. 30, 2020).

[14] Office of Institutional Research \& Planning, Carleton University, "Table SD6- Residency and Fee Status of FullTime and Part-Time Students. Student demographics 2019." http://oirp.carleton.ca/databook/index/html/studentdemographics.htm (accessed Apr. 30, 2020).

[15] Onondaga Nation, "Two Row Wampum - Guswenta," Onondaga Nation: People of the Hills. https:/www.onondaganation.org/culture/wampum/tworow-wampum-belt-guswenta/ (accessed Apr. 28, 2020).

[16] Carleton University Centre for Indigenous Initiatives, "Territory Acknowledgement." https://carleton.ca/indigenous/resources/territoryacknowledgement/ (accessed Apr. 28, 2020).

[17] E. Graham-Harrison, "Hong Kong: Clashes as first charges brought under face mask ban law," The Guardian, Oct. 07, 2019. 